\title{
Alterations in Ventilation-Perfusion Relationships in the Lung after Breathing Inert Dust or Bronchoconstrictor Aero- sols and after Short Periods of Voluntary Hyperventilation
}

\author{
J. M. Raine ANd J. M. Bishop \\ (From the Department of Medicine, University of Birmingham, Queen Elizabeth Hospital, \\ Birmingham, England)
}

The increase in airway resistance that follows the breathing of fine inert dust was first demonstrated by DuBois and Dautrebande (1), who also showed that an aerosol of carbachol had the same effect. The compliance of the lungs was reduced, which led these authors to conclude that the increased airway resistance was unevenly distributed. Constantine and associates (2) confirmed the increased airway resistance in similar experiments and also noted an increase in intrathoracic gas volume, which they attributed to trapping of gas. McDermott (3) found a significant increase in airway resistance after breathing similar dusts at concentrations almost certainly less than those used by the previous workers and more comparable to the concentrations encountered under certain industrial conditions. She also commented on the considerable individual variation in response.

The first part of the present study had two main objectives, the first of which was to determine the extent to which these inhaled materials altered the distribution of alveolar ventilation and to observe the effects this had upon respiratory gas exchange in the lungs. Of at least equal importance was the possibility that the experiments might reveal something of how the distribution of alveolar perfusion responds to an acute alteration in the distribution of alveolar ventilation, and this has influenced the design of the experiments.

During these experiments the possibility arose that the observed effects might result from the associated moderate hyperventilation. A preliminary observation lent support to the idea that hyperventilation was followed by an increase in

* Submitted for publication June 10, 1963; accepted November 21, 1963.

Aided by the Endowment Research Fund of the United Birmingham Hospitals. physiological dead space, and this led to the second series of experiments. The results, which have already been reported briefly (4), showed a prolonged increase in physiological dead space after hyperventilation in the sitting position. This was prevented by substituting a mixture containing carbon dioxide for air during the period of hyperventilation and was much less evident when the subjects were supine.

\section{Methods}

Respiratory gas exchange was investigated by the measurement of the alveolar-arterial difference in oxygen tension $(\mathrm{A}-\mathrm{aD})$ and physiological dead space. Expired gas was collected in a Tissot spirometer for 2 minutes and was analyzed by the Scholander method. During this time three samples of blood for estimation of $\mathrm{Po}_{2}$ and two samples for $\mathrm{PCO}_{2}$ were obtained from a needle in the brachial artery, sampling extending over the whole of the 2-minute period. The $\mathrm{PO}_{2}$ of arterial blood was measured within 10 minutes of sampling by a polythene-covered combined electrode system (5), the standard deviation of an estimate of oxygen tension in the region of $100 \mathrm{~mm} \mathrm{Hg}$ being $0.7 \mathrm{~mm} \mathrm{Hg}$. Arterial $\mathrm{PCO}_{2}$ was measured by a modification of the interpolation method of Åstrup (6). The blood was centrifuged anaerobically at $38^{\circ} \mathrm{C}$, and after the initial $\mathrm{pH}$ reading, the plasma was equilibrated at three known carbon dioxide tensions.

The alveolar oxygen tension was calculated from the alveolar gas equation, assuming arterial carbon dioxide tension to equal alveolar carbon dioxide tension. Physiological dead space was calculated from the Bohr equation, with the same assumption concerning $\mathrm{Paco}_{2}$. The apparatus dead space was subtracted, and the result has also been expressed as a percentage of the tidal volume $\left(\mathrm{V}_{\mathrm{D}} / \mathrm{V}_{\mathrm{T}}\right)$.

The distribution of alveolar ventilation was studied by the single breath oxygen test (7), the test conditions being standardized as suggested by Kjellmer, Sandqvist, and Berglund (8). The volume of oxygen inspired was $1 \mathrm{~L}$, no inspiratory pause was allowed, and the subject 
expired at a rate between 30 and $60 \mathrm{~L}$ per minute. Oxygen was inspired from one spirometer and the subsequent expirate passed to another spirometer, the pulley wheel of which activated two electrical contacts. This caused a break in the recording of nitrogen concentration at 750 and $1,250 \mathrm{ml}$ of expired volume, and results are given as the difference in concentration at these points.

In some subjects anatomical dead space was also measured by the record of nitrogen concentration together with a simultaneous record of expired voiume as described by Fowler (9). In these experiments the inspired volume of oxygen was $500 \mathrm{ml}$. The response time of the nitrogen meter was measured for each series of observations, and the appropriate allowance was also made for the dead space between the lips and the point of gas sampling.

Aerosols of a $2 \%$ solution of carbachol (British Pharmacopoeia) in normal saline were produced with a nebulizer (10) driven from a cylinder of compressed air. It was found that $77 \%$ of the droplets produced were in the size range 1.0 to $1.5 \mu$, and $99 \%$ were smaller than $2.4 \mu$. The aerosol was directed towards the mouth, and the subject took from 20 to 30 inspirations in 3 to 5 minutes, care being taken not to swallow any of the solution which might collect in the mouth.

Calcium carbonate dust was dispersed in the early experiments by directing a jet of air onto the loosely packed powder in a jar. Later a more satisfactory cloud was produced with the Wright dust-feed mechanism (11) using an air flow rate of $8 \mathrm{~L}$ per minute. In each case the cloud passed into a large bottle to allow settling of the larger particles and was then delivered to the subject by a flexible tube of approximately $1.5-\mathrm{cm}$ bore. The subject directed the stream into his mouth and breathed deeply, taking 20 to 30 breaths in about 3 minutes. A study of the particle size of the dust cloud revealed that it was highly aggregated and contained about 120,000 particles per $\mathrm{ml}$ in the range 0.5 to $5.0 \mu$ and about 40,000 per $\mathrm{ml}$ in the range 0.2 to $0.5 \mu$.

Subjects studied. The subjects were 43 healthy men and women, without any history of respiratory or other significant disease, free from cough sputum, or other respiratory symptoms, and ranging in age from 21 to 60 years. They walked to the laboratory and rested for at least 30 minutes before the study commenced. Smoking was not allowed during the hour before the start of the study.

Procedure in bronchoconstrictor and dust studies. All of the measurements were made in the sitting position and when breathing air. Two mouthpieces were suspended close to the subject's mouth so that he could readily change from the circuit used for the single-breath test to that used for the collection of expired gas. After an arterial needle had been inserted in the left brachial artery, the subject performed a few single-breath maneuvers to become familiar with the procedure.

The experimental period started with two control measurements of $\mathrm{A}-\mathrm{aD}$ and physiological dead space, together with three single-breath tests, extending over 15 minutes. The two types of procedure alternated, and at least 3 minutes elapsed between a single-breath test and the next collection of expired gas. The subject then breathed either carbachol aerosol or calcium carbonate dust. Further 5 to 6 measurements of $\mathrm{A}-\mathrm{aD}$ and physiological dead space were made during the next hour, the timing of these varying a little from subject to subject. Single-breath tests were interpolated as in the control period. A further group of subjects acted as controls and underwent the same procedure with the exception that they did not breathe either carbachol aerosol or a dust cloud.

Procedure in hyperventilation studies. The subjects were divided into four groups as follows: Group 1 comprised nine subjects studied before and after hyperventilation, breathing air, in the sitting position. Group 2 comprised four subjects studied before and after hyperventilation, breathing 3 to $5 \%$ carbon dioxide in air, in the sitting position. Group 3 comprised four subjects studied before and after hyperventilation, breathing air, in the supine position. Group 4 comprised nine subjects studied before and after hyperventilation, breathing air, in the sitting position, and who were also given an intravenous infusion of angiotensin 30 to 40 minutes later.

Two control measurements were made before hyper-

TABLE I

Respiratory gas exchange under resting conditions over a period of 1 hour*

\begin{tabular}{|c|c|c|c|c|c|c|c|c|c|}
\hline Time & $\mathrm{PA}_{2}$ & $\mathrm{~Pa}_{2}$ & A-aD & $\mathrm{Pa}_{C_{2}}$ & $\begin{array}{c}\text { VD physiol. } \\
\text { BTPS }\end{array}$ & $\underset{\text { BTPS }}{\mathrm{V}_{\mathrm{T}}}$ & $\mathrm{V}_{\mathrm{D}} / \mathrm{V}_{\mathrm{T}}$ & $\underset{\text { BTPS }}{\dot{V}_{A}}$ & $\mathbf{R}_{\mathbf{E}}$ \\
\hline $\min$ & $m m H g$ & $m m \mathrm{Hg}$ & $m m \mathrm{Hg}$ & $m m H g$ & $m l$ & $m l$ & $\%$ & $L / \min$ & \\
\hline $0-2$ & 106 & 94.9 & 11.1 & 37.1 & 174 & 646 & 26.9 & 6.8 & 0.890 \\
\hline $9-11$ & 108 & 95.6 & 12.4 & 36.7 & 186 & 689 & 27.0 & 7.0 & 0.895 \\
\hline $19-21$ & 109 & 98.1 & 10.9 & 35.8 & 177 & 643 & 27.5 & 7.2 & 0.942 \\
\hline $29-31$ & 109 & 98.5 & 10.5 & 36.1 & 157 & 588 & 26.7 & 6.9 & 0.904 \\
\hline $39-41$ & 107 & 93.1 & 13.9 & 36.9 & 181 & 585 & 30.9 & 6.4 & 0.895 \\
\hline 49-51 & 104 & 93.2 & 10.8 & 38.4 & 172 & 560 & 30.7 & 6.3 & 0.866 \\
\hline $59-61$ & 103 & 91.1 & 11.9 & 39.0 & 185 & 545 & 34.0 & 6.1 & 0.854 \\
\hline
\end{tabular}

* Mean values in five subjects. $\mathrm{PAO}_{2}$, alveolar oxygen tension; $\mathrm{PaO}_{2}$, arterial oxygen tension. $\mathrm{A}-\mathrm{aD}$, alveolar-arterial difference in oxygen tension; $\mathrm{PaCO}_{2}$, arterial carbon dioxide tension; $\mathrm{V}_{\mathrm{D}}$ physiol., physiological dead space; $\mathrm{V}_{\mathrm{T}}$, tidal volume; $\dot{\mathrm{V}}_{\mathbf{A}}$, alveolar ventilation; $\mathrm{R}_{\mathbf{E}}$, respiratory gas exchange ratio; $\mathrm{BTPS}$, body temperature, pressure, saturated with water. 
TABLE II

Individual values for $V_{D} / V_{T}$ and $A-a D$ in five subjects sitting at rest during a period of 1 hour*

\begin{tabular}{|c|c|c|c|c|c|c|c|c|c|c|c|c|c|c|}
\hline \multirow[b]{2}{*}{ Subject } & \multicolumn{7}{|c|}{$\begin{array}{c}\mathrm{V}_{\mathrm{D}} / \mathrm{V}_{\mathrm{T}} \\
\text { Time }(\mathrm{min})\end{array}$} & \multicolumn{7}{|c|}{$\begin{array}{c}\mathrm{A}-\mathrm{aD} \\
\text { Time (min) }\end{array}$} \\
\hline & 0 & 10 & 20 & 30 & 40 & 50 & 60 & 0 & 10 & 20 & 30 & 40 & 50 & 60 \\
\hline & \multicolumn{7}{|c|}{$\%$} & \multicolumn{7}{|c|}{$m m H g$} \\
\hline 1 & 19.8 & 18.9 & 19.2 & 18.7 & 17.5 & 25.3 & 37.9 & 1.0 & 3.0 & 6.0 & 4.0 & 9.0 & 4.0 & 9.1 \\
\hline 2 & 31.3 & 29.8 & 26.2 & 25.4 & 28.7 & 30.5 & 33.2 & 16.1 & 14.5 & 19.8 & 17.3 & 17.5 & 16.9 & 15.0 \\
\hline 3 & 19.9 & 30.6 & 30.0 & 32.0 & 33.9 & 34.5 & 34.9 & 15.1 & 15.3 & 10.5 & 11.4 & 13.2 & 10.0 & 11.2 \\
\hline 4 & 30.3 & 29.6 & 28.9 & 32.1 & 31.3 & 29.8 & 35.6 & 4.2 & 4.0 & 4.8 & 4.5 & 5.6 & 4.3 & 4.1 \\
\hline 5 & 33.3 & 28.5 & 33.4 & 30.4 & 31.9 & 33.4 & 28.5 & 21.4 & 15.8 & 14.3 & 17.3 & 23.2 & 19.3 & 18.3 \\
\hline
\end{tabular}

* Abbreviations as in Table I.

ventilation, and five or more collections were made at intervals from 10 to 70 minutes after hyperventilation. Subjects were encouraged to hyperventilate for $3 \mathrm{~min}$ utes by taking deep breaths but without attempting to increase the rate of breathing. In 19 of the 26 subjects the expired gas was collected during hyperventilation in a Douglas bag, and its volume measured; a sample of arterial blood was also taken during the third minute for measurement of $\mathrm{Paco}_{2}$. The subjects of group 2 breathed, during hyperventilation, a mixture containing 3 to $5 \%$ $\mathrm{CO}_{2}$ in air, which was delivered from a cylinder through an anesthesia bag acting as a reservoir.

In the subjects of group 4, a slow intravenous infusion of normal saline was set up before measurements started. At a time ranging from 33 to 42 minutes after hyperventilation, a solution of synthetic angiotensin was substituted for the normal saline and was delivered by a constant infusion pump at the rate of $2 \mu \mathrm{g}$ per minute for 5 to 12 minutes. Further measurements were made during and after infusion.

\section{Results}

These are given in the Tables and Figures and are described under several headings below. The mean values for the more important measurements are given for each series of experiments, and, where appropriate, individual values for $\mathrm{A}-\mathrm{aD}$ and $\mathrm{V}_{\mathrm{D}} / \mathrm{V}_{\mathrm{T}}$ are also presented.

\section{Control observations without inhalation or hy- perventilation}

The mean results obtained in five subjects in whom measurements were made at rest over a period of an hour without inhalation or hyperventilation are presented in Table I. Individual values for $V_{D} / V_{T}$ and $A-a D$ are given in Table II.

TABLE III

Respiratory gas exchange before and after inhalation of carbachol aerosol*

\begin{tabular}{|c|c|c|c|c|c|c|c|c|c|c|}
\hline Timet & $\mathrm{PA}_{\mathrm{O}_{2}}$ & $\mathrm{~Pa}_{2}$ & $A-a D$ & $\mathrm{PaCO}_{2}$ & $\begin{array}{c}\text { VD physiol. } \\
\text { BTPS }\end{array}$ & $\begin{array}{c}\mathrm{VT}_{\mathrm{T}} \\
\mathrm{BTPS}\end{array}$ & $\mathrm{V}_{\mathrm{D}} / \mathrm{V}_{\mathrm{T}}$ & $\begin{array}{c}\dot{\mathrm{V}}_{\mathrm{A}} \\
\mathrm{BTPS}\end{array}$ & $\mathbf{R}_{\mathbf{E}}$ & $\begin{array}{c}\mathrm{N}_{2} \\
\text { difference }\end{array}$ \\
\hline $\min$ & $m m \mathrm{Hg}$ & $m m \mathrm{Hg}$ & $m m \mathrm{Hg}$ & $m m \mathrm{Hg}$ & $m l$ & $m l$ & $\%$ & $L / \min$ & & $\%$ \\
\hline Control & 108 & 106 & 2.0 & 36.5 & 128 & 592 & 21.6 & 6.7 & 0.958 & \multirow{2}{*}{$1.1 \ddagger$} \\
\hline Control & 104 & 102 & 3.0 & 38.6 & 145 & 575 & 25.2 & 5.6 & 0.914 & \\
\hline \multirow{7}{*}{$\begin{array}{c}1 \\
4-6 \\
7 \\
10-12 \\
12-15 \\
17-19 \\
20-29 \\
36-38 \\
30-39 \\
40-49 \\
50-59 \\
60-62 \\
65\end{array}$} & \multirow[b]{2}{*}{95.0} & \multirow[b]{2}{*}{74.3} & \multirow[b]{2}{*}{20.7} & \multirow[b]{2}{*}{36.9} & \multirow[b]{2}{*}{126} & \multirow[b]{2}{*}{500} & \multirow[b]{2}{*}{25.2} & \multirow[b]{2}{*}{4.4} & \multirow[b]{2}{*}{0.705} & \multirow{2}{*}{1.9} \\
\hline & & & & & & & & & & \\
\hline & 96.3 & 78.2 & 18.1 & 39.4 & 117 & 492 & 23.8 & 4.4 & 0.724 & \multirow{2}{*}{2.5} \\
\hline & 102 & 82.3 & 19.7 & 39.1 & 144 & 550 & 26.2 & 5.1 & 0.851 & \\
\hline & 102 & 92.1 & 9.9 & 40.8 & 136 & 541 & 25.1 & 4.6 & 0.851 & 2.1 \\
\hline & & & & & & & & & & $\begin{array}{l}2.1 \\
1.8 \\
1.8\end{array}$ \\
\hline & 101 & 97.6 & 3.4 & 40.5 & 148 & 592 & 25.0 & 4.9 & 0.848 & 1.7 \\
\hline
\end{tabular}

* Mean values in four subjects. Abbreviations as in Table I.

$\dagger$ Time in minutes from end of period of carbachol inhalation.

$\ddagger$ Mean of 3 measurements in each subject. 
TABLE IV

Individual values for $V_{D} / V_{T}$ and $A-a D$ before and after breathing carbachol aerosol and calcium carbonate dust*

\begin{tabular}{|c|c|c|c|c|c|c|c|c|c|c|c|c|c|c|c|}
\hline & \multirow[b]{2}{*}{ Subject } & \multicolumn{7}{|c|}{$\begin{array}{c}\qquad V_{D} / V_{T} \\
\text { Time after bronchoconstrictor (min) }\end{array}$} & \multicolumn{7}{|c|}{ Time after bronchoconstrictor (min) } \\
\hline & & $\mathrm{C}_{1} \dagger$ & $\mathrm{C}_{2}$ & $4-6$ & $10-12$ & 17-19 & $36-38$ & $60-62$ & $C_{1}$ & $\mathrm{C}_{2}$ & $4-6$ & $10-12$ & $17-19$ & $36-38$ & $60-62$ \\
\hline & & \multicolumn{7}{|c|}{$\%$} & \multicolumn{7}{|c|}{$m m ~ H g$} \\
\hline \multirow{8}{*}{$\begin{array}{l}\text { Calcium carbonate } \\
\text { dust }\end{array}$} & 1 & 14.0 & 19.8 & 22.4 & 29.0 & 24.0 & 27.6 & 26.2 & -3.0 & -2.8 & 5.2 & -1.5 & 1.3 & -3.1 & -8.8 \\
\hline & 2 & 20.5 & 21.4 & 22.2 & 17.1 & 19.1 & 18.5 & 17.4 & 2.0 & 7.0 & 16.8 & 8.7 & 10.6 & 5.0 & 4.0 \\
\hline & 3 & 36.9 & 32.6 & 37.9 & 40.9 & 34.1 & 36.3 & 39.5 & -3.8 & 0.8 & 13.8 & 15.0 & 9.7 & -2.5 & -7.9 \\
\hline & 4 & 27.5 & 25.5 & 31.8 & 33.1 & 34.5 & 31.4 & 33.3 & -0.3 & 4.5 & 15.7 & 1.8 & -1.3 & -1.0 & -1.4 \\
\hline & 5 & 17.6 & 18.1 & 27.1 & 20.2 & 27.9 & 26.6 & 25.7 & 7.3 & 7.5 & 34.0 & 35.5 & 24.1 & 13.1 & 11.9 \\
\hline & 6 & 20.5 & 20.6 & 25.5 & 25.5 & 24.6 & 16.8 & 18.9 & 18.0 & 18.4 & 30.9 & 29.9 & 18.0 & 17.0 & 16.7 \\
\hline & 7 & 28.5 & 23.9 & 27.9 & 24.6 & 27.6 & 24.3 & 24.1 & -0.5 & 3.4 & 15.9 & 11.9 & 5.2 & 5.5 & 8.3 \\
\hline & 8 & 19.9 & 20.9 & 32.9 & 30.4 & 38.1 & 39.7 & 30.3 & 18.0 & 15.0 & 23.7 & 24.0 & 22.0 & 12.1 & 14.9 \\
\hline \multirow[t]{4}{*}{ Carbachol aerosol } & 1 & 21.0 & 23.8 & 26.9 & 22.9 & 30.9 & & 25.0 & 4.7 & 6.1 & 24.5 & 24.8 & 22.8 & & 0.9 \\
\hline & 2 & 27.4 & 28.4 & 27.0 & 29.3 & 33.1 & 25.1 & 26.0 & 1.0 & 1.0 & 8.9 & 9.5 & 7.7 & 6.4 & 1.0 \\
\hline & 3 & 16.6 & 25.6 & 24.9 & 20.4 & 22.3 & 26.3 & 28.9 & -0.7 & 2.6 & 22.4 & 17.9 & 17.0 & 4.1 & 2.8 \\
\hline & 4 & 21.2 & 22.8 & 21.9 & 22.7 & 18.6 & 23.8 & 21.1 & 4.0 & 1.0 & 27.3 & 20.9 & 29.5 & 18.5 & 7.0 \\
\hline
\end{tabular}

* Abbreviations as in Table $I$

$+C_{1}$ and $C_{2}$, first and second control observations.

In describing the results, in the following sections, it has been found helpful to consider the changes at each time interval from the mean of the control observations made before the inhalation of the bronchoconstrictor or before hyperventilation.
The results from Table I have therefore been treated in the same way, the changes at each time interval from the mean of the first and second measurements being calculated. The mean changes in $\mathrm{A}-\mathrm{aD}$ and $\mathrm{V}_{\mathbf{D}} / \mathrm{V}_{\mathbf{T}}$ are presented in Figures 2

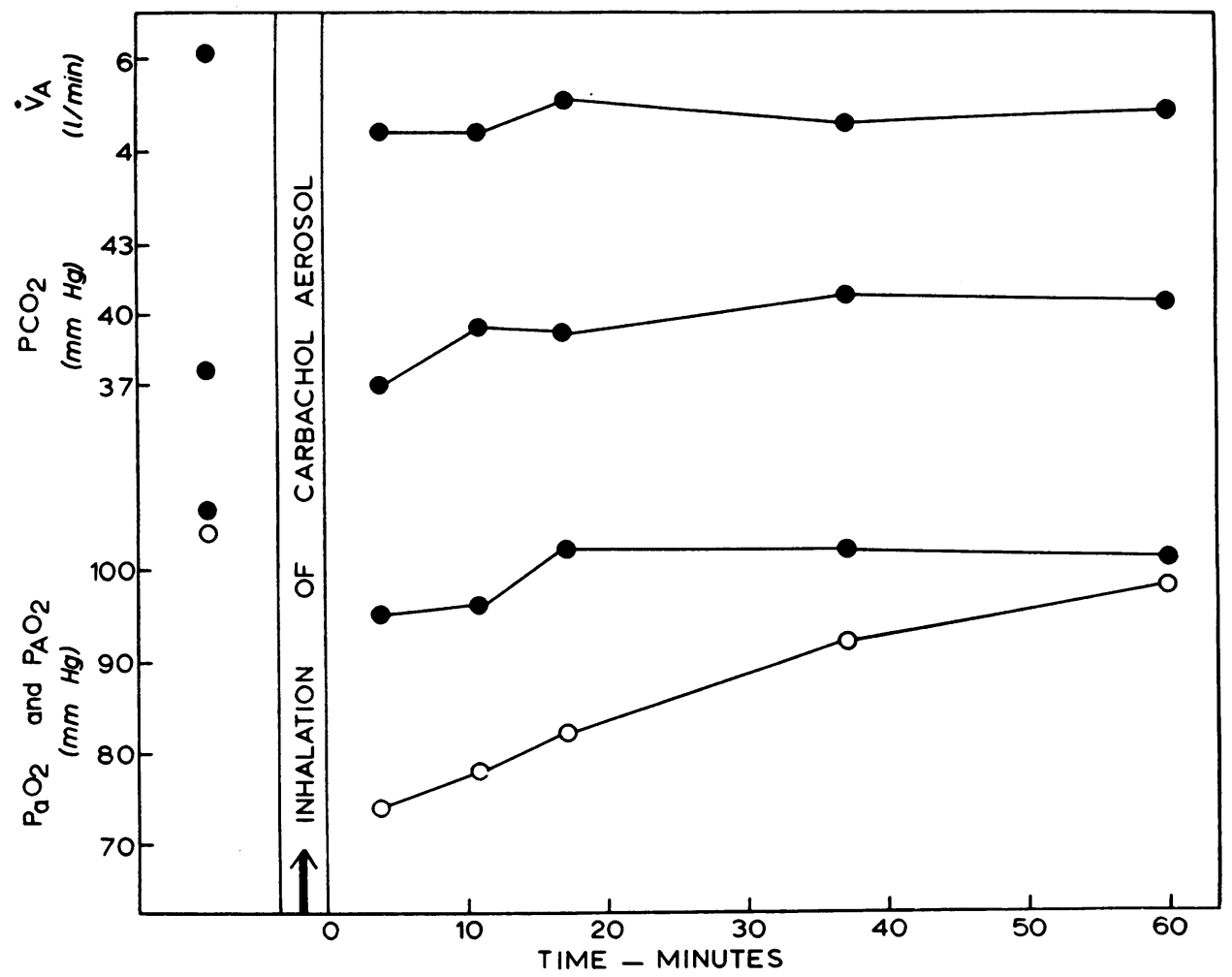

Fig. 1. Alveolar ventilation (Via), arterial Carbon dioxide tension $\left(\mathrm{PcO}_{2}\right)$, and

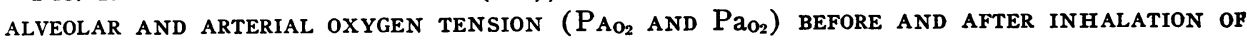
CARBACHOL AEROSOL. Mean values from four subjects. 
TABLE $V$

Values for anatomical dead space before and after breathing dust or carbachol aerosol or voluntary hyperventilation

\begin{tabular}{lccc}
\hline \hline & Subject & Control & $\begin{array}{c}\text { After test } \\
\text { procedure }\end{array}$ \\
\hline Calcium & & $m l$ & $m l$ \\
$\quad$ carbonate & 11 & $142[2]^{*}$ & $144[5]$ \\
& 12 & $190[2]$ & $185[7]$ \\
Carbachol & 13 & $184[2]$ & $185[3]$ \\
Hyperventilation, & 15 & $143[2]$ & $155[3]$ \\
breathing air, & 16 & $220[2]$ & $255[6]$ \\
sitting & 17 & $100[3]$ & $100[8]$ \\
& 18 & $73[3]$ & $61[9]$
\end{tabular}

* Values in brackets indicate number of measurements in each subject.

and 4, together with similar data for nitrogen concentration difference, not given in the Tables. The variations in the $\mathrm{A}-\mathrm{aD}, \mathrm{V}_{\mathrm{D}} / \mathrm{V}_{\mathrm{T}}$, and the nitrogen concentration difference during this time were small; only in the case of $V_{D} / V_{T}$ was there even a suggestion of a trend towards the end of the period of observation, and this was not significant.

\section{Effects of carbachol aerosol}

The mean results in four subjects who breathed carbachol aerosol are given in Table III. Indi-

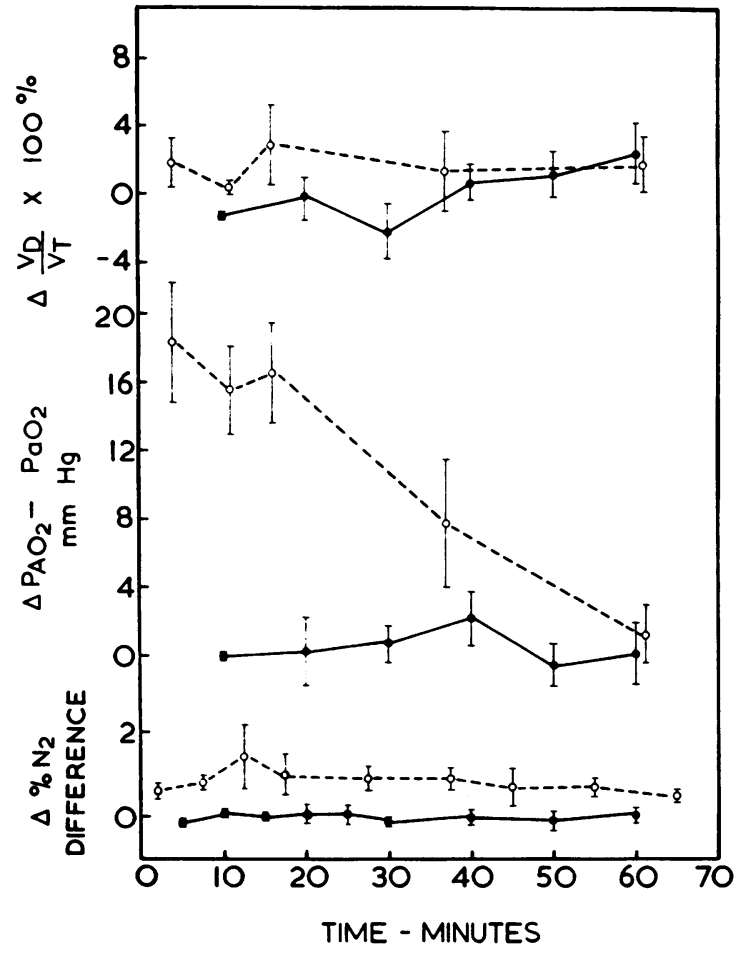

Fig. 2. Changes in physiological dead Space ( $\mathrm{V}_{\mathrm{D}} /$ $\mathrm{V}_{\mathrm{T}}$ ), ALVEOLAR-ARTERIAL DIFFERENCE IN OXYGEN TENSION (A-aD), AND NITROGEN CONCENTRATION DIFFERENCE AFTER INHALATION OF CARBACHOL AEROSOL (broken lines) AND IN CONTROL SUBJECTS (continuous lines). The inhalation was completed at zero time. Mean values from four subjects, $\pm \mathrm{SE}$.

TABLE VI

Respiratory gas exchange before and after inhalation of calcium carbonate dust*

\begin{tabular}{|c|c|c|c|c|c|c|c|c|c|c|}
\hline Timet & $\mathrm{PA}_{\mathrm{O}_{2}}$ & $\mathrm{PaO}_{2}$ & $\mathrm{~A}-\mathrm{aD}$ & $\mathrm{PacO}_{2}$ & $\begin{array}{c}\text { VD physiol. } \\
\text { BTPS }\end{array}$ & $\underset{\text { BTPS }}{V_{T}}$ & $\mathrm{~V}_{\mathrm{D}} / \mathrm{V}_{\mathbf{T}}$ & $\underset{\mathrm{BTPS}}{\dot{\mathrm{V}}_{\mathrm{A}}}$ & $\mathbf{R}_{\mathbf{E}}$ & $\begin{array}{c}\mathrm{N}_{2} \\
\text { difference }\end{array}$ \\
\hline $\min$ & $m m \mathrm{Hg}$ & $m m \mathrm{Hg}$ & $m m \mathrm{Hg}$ & $\mathrm{mm} \mathrm{Hg}^{2}$ & $m l$ & $m l$ & $\%$ & $L / \min$ & & $\%$ \\
\hline Control & 101 & 96.2 & 4.8 & 39.3 & 173 & 745 & 23.2 & 7.0 & 0.944 & \multirow{2}{*}{$1.9 \ddagger$} \\
\hline Control & 98.1 & 91.3 & 6.8 & 39.3 & 138 & 603 & 22.9 & 5.7 & 0.815 & \\
\hline $2-5$ & 90.2 & 70.7 & 19.5 & 37.3 & 148 & 520 & 28.5 & 4.4 & 0.660 & \multirow{2}{*}{3.2} \\
\hline $\begin{array}{c}8-11 \\
9\end{array}$ & 94.3 & 78.7 & 15.6 & 39.1 & 161 & 581 & 27.7 & 5.6 & 0.767 & \\
\hline 14 & 96.5 & 853 & 112 & & & & & & & $\begin{array}{l}2.1 \\
2.6\end{array}$ \\
\hline $\begin{array}{l}10-18 \\
15-19\end{array}$ & 90.5 & 85.3 & 11.2 & 40.6 & 173 & 604 & 28.7 & 5.4 & 0.820 & \multirow{2}{*}{$\begin{array}{l}2.0 \\
2.4\end{array}$} \\
\hline $\begin{array}{l}20-29 \\
34-36\end{array}$ & 96.7 & 90.9 & 5.8 & 42.1 & 173 & 625 & 27.7 & 5.6 & 0.876 & \\
\hline $\begin{array}{l}30-39 \\
40-49 \\
50-59\end{array}$ & & & & & & & & & & $\begin{array}{l}2.4 \\
2.4 \\
1.6\end{array}$ \\
\hline $\begin{array}{c}60-62 \\
70\end{array}$ & 97.8 & 93.1 & 4.7 & 40.6 & 166 & 617 & 26.9 & 5.6 & 0.867 & 1.8 \\
\hline $\begin{array}{c}80-82 \\
85\end{array}$ & 99.0 & 93.6 & 5.4 & 39.9 & 151 & 619 & 24.4 & 6.1 & 0.869 & 1.7 \\
\hline
\end{tabular}

* Mean values in eight subjects. Abbreviations as in Table I.

+ Time in minutes from end of period of inhalation of calcium carbonate.

$\ddagger$ Mean of 3 measurements in each subject. 


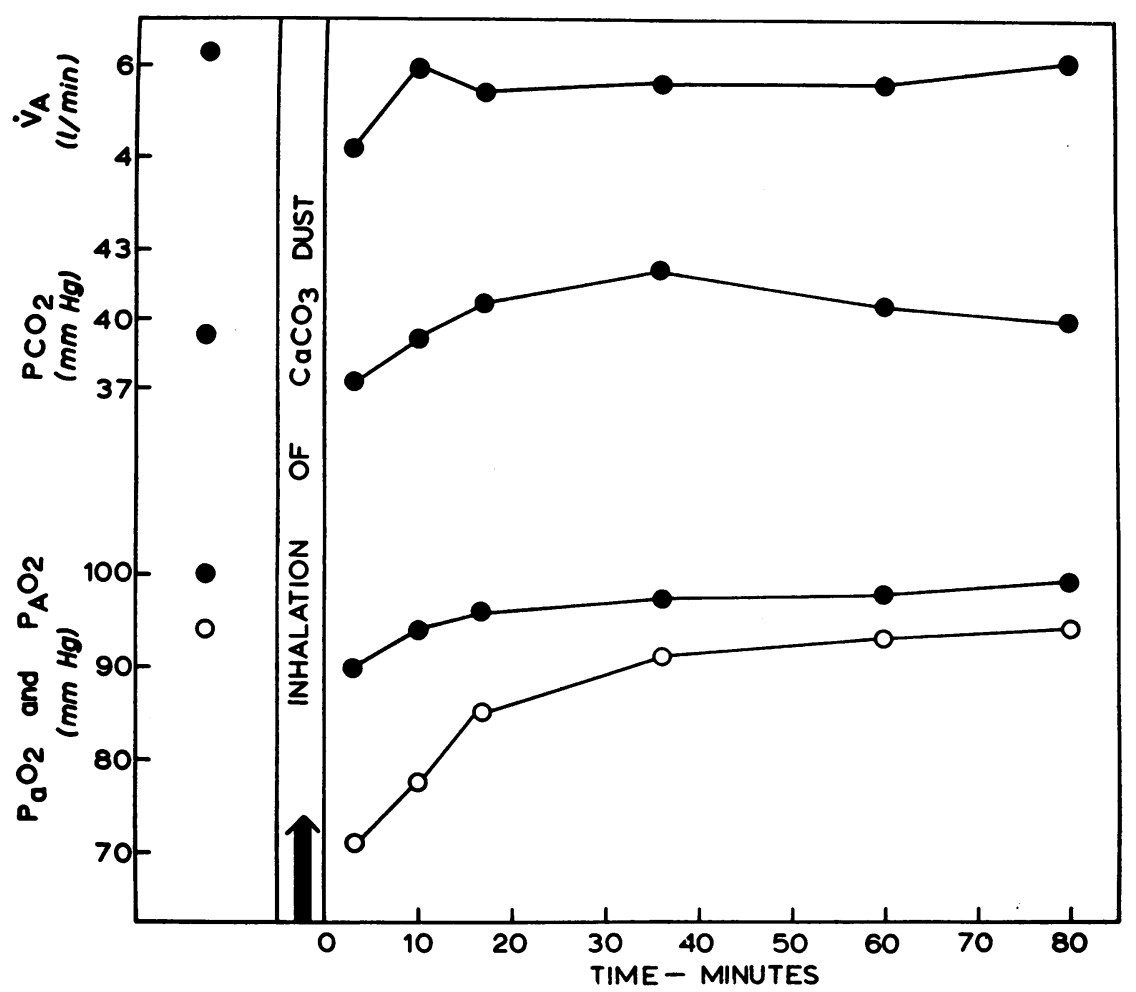

Fig. 3. Alveolar ventilation, arterial carbon dioxide tension, and alveolar AND ARTERIAL OXYGEN TENSION BEFORE AND AFTER BREATHING CALCIUM CARBONATE DUST CLOUdS. Mean values from eight subjects.

vidual values for $V_{D} / V_{T}$ and $A-a D$ are shown in Table IV. After breathing the bronchoconstrictor, the expired volume fell as also did the alveolar ventilation. Tidal volume decreased at first and then returned towards the control value. The respiratory exchange ratio decreased, but there was no significant change in $\mathrm{Pa}_{\mathrm{CO}_{2}}$. These features are illustrated in Figure 1, which also shows the fall in alveolar oxygen tension associated with the decreased alveolar ventilation. Arterial oxygen tension, however, fell much more than the alveolar tension with a resultant increase in $\mathrm{A}-\mathrm{aD}$ which had returned to the control value only after one hour.

The changes in $\mathrm{A}-\mathrm{aD}, \mathrm{V}_{\mathrm{D}} / \mathrm{V}_{\mathrm{T}}$, and the nitrogen concentration difference after carbachol inspiration are shown in Figure 2 with, for comparison, the changes in the control subjects described above. The significance of the changes after carbachol inspiration has been determined by comparing the mean change at each time interval with the mean change observed in the control group of subjects at a comparable time.
There was an increase in the nitrogen concentration difference, and this remained significantly greater for 60 minutes after carbachol inspiration. The increase in $\mathrm{A}-\mathrm{aD}$ occurred in all subjects and was greatest at the first measurement, 4 minutes after carbachol, thereafter decreasing progressively. The increase was significant up to minute 16. There was no change in physiological dead space, and a slight but insignificant increase in $\mathrm{V}_{\mathbf{D}} / \mathrm{V}_{\mathbf{T}}$. In the one subject in whom it was measured, anatomical dead space decreased by $54 \mathrm{ml}$ after carbachol inspiration (Table V).

\section{Effects of calcium carbonate dust}

The mean results in eight subjects are presented in Table VI, and individual values for $V_{D} / V_{T}$ and $\mathrm{A}-\mathrm{aD}$ are given in Table IV. The expired volume and alveolar ventilation decreased, and there was a small fall in $\mathrm{Pa}_{\mathrm{CO}_{2}}$ and respiratory exchange ratio. Tidal volume was reduced at the first measurement after dust but soon returned to control levels. Figure 3 illustrates these changes together with the fall in alveolar oxygen 


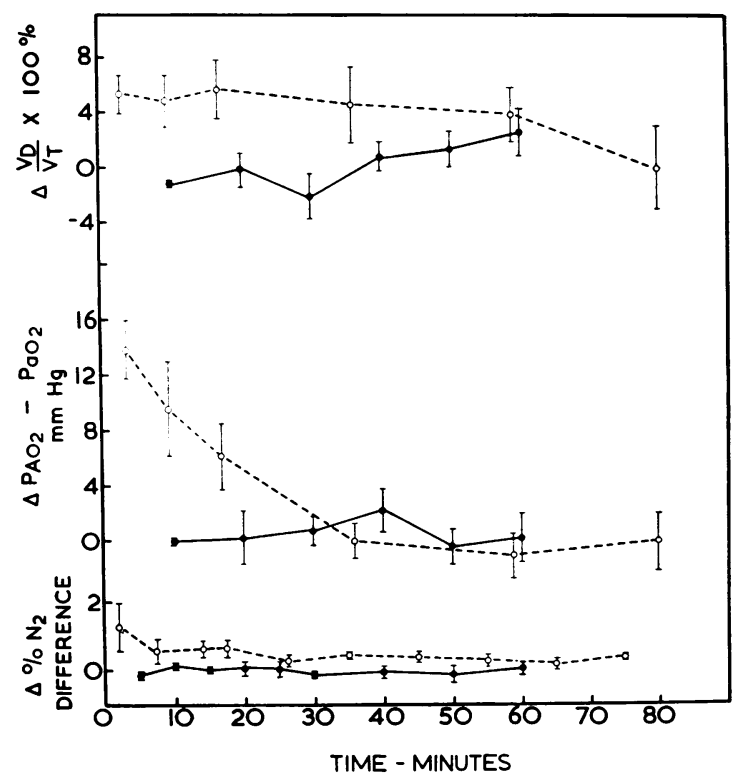

Fig. 4. Changes in Physiological dead space, alveoLAR-ARTERIAL DIFFERENCE IN OXYGEN TENSION, AND NITROGEN CONCENTRATION DIFFERENCE AFTER INHALATION OF CALCIUM CARBONATE DUST CLOUDS (broken lines) AND IN CONTROL SLBJECTS (continuous lines). The inhalation was completed at zero time. Mean values from eight subjects, $\pm \mathrm{SE}$.

tension and the greater fall in arterial oxygen tension. The increase in $\mathrm{A}-\mathrm{aD}$ is not so great as after carbachol and by 36 minutes the $\mathrm{A}-\mathrm{aD}$ had regained its original value.
The changes in $\mathrm{A}-\mathrm{aD}, \mathrm{V}_{\mathrm{D}} / \mathrm{V}_{\mathrm{T}}$, and the nitrogen concentration difference are shown in Figure 4, together with the control values. The nitrogen concentration difference increased in all subjects, but the changes were somewhat variable, and the mean increase was only significant until 14 minutes after the inhalation. $\mathrm{A}-\mathrm{aD}$ increased in each subject, was greatest at the first measurement, 2 minutes after breathing dust, and decreased thereafter, the increase remaining significant up to 8 minutes after breathing the dust. Physiological dead space increased in most of the subjects, but the mean changes were not significant at any time. In contrast to the subjects who breathed carbachol, $V_{D} / V_{T}$ increased in five of the eight subjects immediately after the dust and remained elevated for an hour. In the remaining three subjects there was no change. The mean increase was significant for the first 17 minutes. Anatomical dead space was measured in three subjects (Table V), and no change was detected after breathing calcium carbonate dust.

\section{Effects of voluntary hyperventilation}

a) Hyperventilation, breathing air, in sitting position. Individual values for $\mathrm{A}-\mathrm{aD}$ and $\mathrm{V}_{\mathrm{D}} / \mathrm{V}_{\mathbf{T}}$ are shown in Table VII, and the mean results are given in Table VIII. The mean expired volume

TABLE VII

Individual values for $V_{D} / V_{T}$ and $A-a D$ before and after hyperventilation*

\begin{tabular}{|c|c|c|c|c|c|c|c|c|c|c|c|c|c|c|c|}
\hline & \multirow[b]{2}{*}{ Subject } & \multicolumn{7}{|c|}{$\begin{array}{c}\mathrm{V}_{\mathrm{D}} / \mathrm{V}_{\mathrm{T}} \\
\text { Time after hyperventilation (min) }\end{array}$} & \multicolumn{7}{|c|}{ Time after hyperventilation (min) } \\
\hline & & $\mathrm{C}_{1 \dagger}$ & $\mathrm{C} 2$ & 10 & 20 & 30 & 45 & 60 & $\mathrm{C}_{1}$ & $\mathrm{C} 2$ & 10 & 20 & 30 & 45 & 60 \\
\hline & & & & & $\%$ & & & & & & & $m m H g$ & & & \\
\hline \multirow{9}{*}{$\begin{array}{l}\text { Hyperventilation, } \\
\text { breathing air, } \\
\text { sitting }\end{array}$} & 1 & 26.7 & 26.5 & 29.4 & 31.5 & 34.9 & 38.4 & 40.1 & 0.9 & 5.3 & 5.6 & -4.3 & -1.2 & -0.5 & -2.2 \\
\hline & 2 & 13.1 & 15.6 & 19.7 & 15.8 & 21.6 & 22.3 & 31.3 & 19.3 & 25.6 & 24.4 & 18.4 & 23.5 & 17.4 & 12.5 \\
\hline & 3 & 19.0 & 22.5 & 27.3 & 25.4 & 32.9 & 32.0 & 28.0 & 21.8 & 22.4 & 19.9 & 24.8 & 18.4 & 20.6 & 25.4 \\
\hline & 4 & 13.9 & 18.6 & 29.8 & 28.0 & 29.8 & 30.5 & 29.9 & 29.2 & 22.2 & 19.7 & 22.5 & 18.3 & 14.9 & 16.1 \\
\hline & 5 & 18.5 & 23.8 & 27.6 & 26.0 & 24.2 & 23.0 & 22.3 & 4.4 & 1.7 & 4.0 & 9.5 & 1.0 & 2.0 & 2.0 \\
\hline & 6 & 18.3 & 14.9 & 24.7 & 29.9 & 28.3 & 25.2 & 23.1 & 17.3 & 14.9 & 11.1 & 6.5 & 9.8 & 9.1 & 10.9 \\
\hline & 7 & 22.4 & 21.0 & 33.2 & 37.2 & 32.3 & 32.4 & 32.5 & 25.0 & 24.9 & 27.4 & 36.0 & 29.0 & 30.0 & 32.3 \\
\hline & 8 & 34.2 & 31.1 & 39.0 & 40.3 & 40.3 & 35.6 & 38.5 & 18.7 & 21.4 & 18.0 & 14.6 & 25.4 & 14.6 & 13.3 \\
\hline & 9 & 19.9 & 27.5 & 25.0 & 22.5 & 26.5 & 27.4 & 27.7 & 12.0 & 5.6 & 4.0 & 3.0 & 5.0 & 2.0 & 3.0 \\
\hline \multirow{4}{*}{$\begin{array}{l}\text { Hyperventilation, } \\
\text { breathing } 3 \text { to } 5 \% \\
\mathrm{CO}_{2} \text {, sitting }\end{array}$} & 10 & 25.4 & 27.4 & 26.2 & 27.8 & 27.1 & 25.6 & 23.4 & 14.0 & 15.7 & 17.0 & 17.0 & 12.0 & 15.0 & 20.0 \\
\hline & 11 & 35.8 & 35.8 & 26.1 & 29.9 & 27.8 & 35.5 & 32.8 & 8.0 & 8.7 & 9.0 & 7.0 & 14.9 & 3.0 & 8.8 \\
\hline & 12 & 37.8 & 39.4 & 38.6 & 39.1 & 44.1 & 42.0 & 39.0 & 16.5 & 15.8 & 16.6 & 12.4 & 5.4 & & 11.1 \\
\hline & 13 & 16.2 & 23.0 & 13.3 & 15.0 & 16.0 & 17.5 & 13.2 & 8.8 & 13.0 & 15.6 & 15.5 & & 13.0 & 6.0 \\
\hline \multirow{4}{*}{$\begin{array}{l}\text { Hyperventilation, } \\
\text { breathing air, } \\
\text { supine }\end{array}$} & 14 & 24.1 & 19.6 & 28.2 & 31.1 & 30.8 & 24.1 & 24.6 & 25.1 & 23.2 & 16.6 & 25.3 & 21.9 & 22.0 & 21.3 \\
\hline & 15 & 31.8 & 29.5 & 29.5 & 28.1 & 28.6 & 32.7 & 30.3 & 3.6 & -0.8 & 1.3 & -3.7 & 0.1 & -1.9 & 1.9 \\
\hline & 16 & 19.7 & 26.2 & 39.8 & 27.1 & 25.6 & 27.5 & 26.5 & 7.2 & 5.4 & 9.0 & 3.9 & 5.6 & 1.9 & 3.7 \\
\hline & 17 & 24.5 & 24.5 & 30.1 & 26.1 & 25.8 & 21.7 & 23.9 & 1.9 & 2.5 & 3.6 & 6.5 & 4.2 & 10.2 & 11.1 \\
\hline
\end{tabular}

* Abbreviations as in Table I.

$+\mathrm{C} 1$ and $\mathrm{C} 2$, first and second control observations. 
TABLE VIII

Mean values in nine subjects before and after hyperventilation, breathing air, in sitting position*

\begin{tabular}{|c|c|c|c|c|c|c|c|c|c|c|}
\hline Time† & $\mathrm{P}_{\mathrm{A}_{O_{2}}}$ & $\mathrm{PaO}_{2}$ & $A-a D$ & $\mathrm{~Pa}_{\mathrm{CO}_{2}}$ & $\mathbf{R}_{\mathbf{E}}$ & $\begin{array}{l}V_{D \text { physiol. }} \\
\text { BTPS }\end{array}$ & $\underset{\mathrm{BTPS}}{\mathrm{V}_{\mathrm{T}}}$ & $\mathrm{V}_{\mathrm{D}} / \mathrm{V}_{\mathrm{T}}$ & $\dot{\mathrm{B}}_{\mathrm{APS}}$ & $\begin{array}{c}\mathrm{N}_{2} \\
\text { difference }\end{array}$ \\
\hline $\begin{array}{c}\min \\
\text { Control }\end{array}$ & $\begin{array}{c}m m \mathrm{Hg} \\
108\end{array}$ & $\begin{array}{c}m m \mathrm{Hg} \\
91.6\end{array}$ & $\begin{array}{c}m m H_{g} \\
16.4\end{array}$ & $\begin{array}{c}m m \mathrm{Hg} \\
35.8\end{array}$ & 0.884 & $\begin{array}{c}m l \\
141\end{array}$ & $\begin{array}{l}m l \\
680\end{array}$ & $\begin{array}{c}\% \\
20.7\end{array}$ & $\begin{array}{c}L / \min \\
7.1\end{array}$ & $\%$ \\
\hline Control & 106 & 90.0 & 16.0 & 36.6 & 0.866 & 145 & 641 & 22.4 & 6.6 & $3.4 \ddagger$ \\
\hline 10 & 102 & 87.3 & 14.7 & 37.7 & 0.770 & 167 & 588 & 28.4 & 5.3 & \multirow{2}{*}{3.1} \\
\hline 20 & 105 & 90.4 & 14.6 & 37.1 & 0.855 & 165 & 579 & 28.5 & 6.1 & \\
\hline 30 & 104 & 89.5 & 14.5 & 37.7 & 0.848 & 176 & 585 & 30.1 & 5.6 & . \\
\hline 45 & 104 & 91.4 & 12.6 & 38.5 & 0.819 & 177 & 598 & 29.6 & 5.2 & 3 \\
\hline 60 & 104 & 91.0 & 13.0 & 38.4 & 0.849 & 189 & 621 & 30.4 & 5.8 & $\begin{array}{l}4.1 \\
3.6\end{array}$ \\
\hline
\end{tabular}

* Abbreviations as in Table $\mathrm{I}$.

$\dagger$ Time from end of period of hyperventilation.

$\ddagger$ Mean of 3 measurements in each subject.

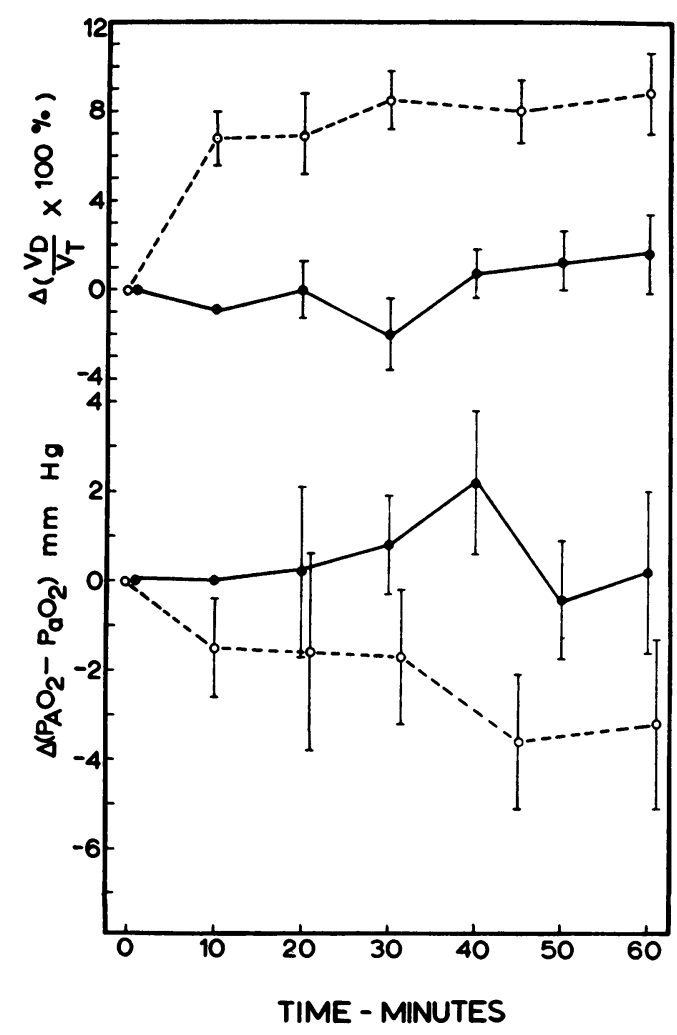

Fig. 5. Change in Physiological dead SPace AND ALVEOLAR-ARTERIAL DIFFERENCE IN OXYGEN TENSION AFTER HYPERVENTILATION, IN SITTING POSTURE, BREATHING AIR. Hyperventilation ceased at zero time. Mean values $\pm \mathrm{SE}$ for nine subjects who hyperventilated are shown by broken line and for five control subjects by continuous line. during the period of hyperventilation, in the seven subjects in whom it was measured, was $30.7 \mathrm{~L}$ per minute, and mean $\mathrm{Pa}_{\mathrm{CO}_{2}}$ at this time was 20.6 $\mathrm{mm} \mathrm{Hg}$ (range, 15.7 to 23.6 ).

The mean expired volume and tidal volume were smaller after hyperventilation than before, but the decrease was no greater than that in the control subjects described in section I. Physiological dead space increased after hyperventilation and remained elevated until minute 45 . In eight of the nine subjects the ratio $V_{D} / V_{T}$ increased and remained elevated for more than 60 minutes showing no tendency to decrease. The mean value before hyperventilation was $21.6 \%$, and from 10 to 70 minutes afterwards it ranged from 28.4 to $30.4 \%$. The $\mathrm{A}-\mathrm{aD}$ decreased in four subjects and remained unaltered in the remaining five subjects.

The changes in physiological dead space, $\mathrm{V}_{\mathbf{D}} / \mathrm{V}_{\mathbf{T}}$, and $\mathrm{A}-\mathrm{aD}$, from the average value before hyperventilation, were calculated for each time interval, and the mean values for the latter two indexes are shown in Figure 5. The increases in physiological dead space and $V_{D} / V_{T}$ were significantly greater than in the control group throughout ( $\mathrm{p}$ in each case ranging from $<0.02$ to $<0.001)$. There was a slight decrease in $\mathrm{A}-\mathrm{aD}$, but except for the value at 45 minutes, the change was not significant. There was no alteration in the nitrogen concentration difference in the single-breath test, the mean values before 
TABLE IX

Mean values in four subjects before and after hyperventilation, breathing $\mathrm{CO}_{2}$ in air, in sitting position*

\begin{tabular}{|c|c|c|c|c|c|c|c|c|c|}
\hline Timet & $\mathrm{PAO}_{2}$ & $\mathrm{PaO}_{2}$ & A-aD & $\mathrm{PaCO}_{2}$ & $\mathbf{R}_{\mathbf{E}}$ & $\begin{array}{c}\text { VD physiol. } \\
\text { BTPS }\end{array}$ & $\begin{array}{c}\text { VT }_{\text {T }} \\
\text { BTS }\end{array}$ & $\mathrm{V}_{\mathbf{D}} / \mathrm{V}_{\mathbf{T}}$ & $\dot{\mathrm{VT}}_{\mathbf{A}}$ \\
\hline $\min$ & $m m \mathrm{Hg}$ & $m m H g$ & $m m H g$ & $m m H g$ & & $m l$ & $m l$ & $\%$ & $L / \min$ \\
\hline Control & 102 & 90.5 & 11.5 & 39.5 & 0.849 & 192 & 666 & 28.8 & 5.7 \\
\hline Control & 106 & 92.5 & 13.5 & 37.7 & 0.907 & 183 & 582 & 31.4 & 5.8 \\
\hline 10 & 111 & 96.4 & 14.6 & 35.7 & 0.980 & 184 & 708 & 26.0 & 7.0 \\
\hline 20 & 109 & 96.3 & 12.7 & 36.7 & 0.954 & 200 & 717 & 27.9 & 7.2 \\
\hline 30 & 105 & 93.8 & 11.2 & 37.5 & 0.886 & 198 & 739 & 28.8 & 6.1 \\
\hline 45 & 106 & 96.5 & 9.5 & 38.5 & 1.060 & 199 & 660 & 30.1 & 6.6 \\
\hline 60 & 107 & 95.9 & 11.1 & 36.0 & 0.896 & 157 & 580 & 27.1 & 5.9 \\
\hline
\end{tabular}

* Abbreviations as in Table I.

$\dagger$ 'Time from end of period of hyperventilation.

and after hyperventilation being 3.4 and $3.6 \%$, respectively. Anatomical dead space was measured in four subjects and increased after hyperventilation in two, decreased in one, and did not change in the remaining subject (Table V). The mean value was $134 \mathrm{ml}$ before and $143 \mathrm{ml}$ after hyperventilation.

b) Hyperventilation, breathing carbon dioxide in air, sitting. Individual values for $\mathrm{A}-\mathrm{aD}$ and $\mathrm{V}_{\mathrm{D}} / \mathrm{V}_{\mathrm{T}}$ are given in Table VII and the mean results in Table IX. The average expired volume during hyperventilation was $22.4 \mathrm{~L}$ per minute, and the average $\mathrm{Pa}_{\mathrm{CO}_{2}}$ was $38.8 \mathrm{~mm} \mathrm{Hg}$. The changes in $V_{\mathbf{D}} / \mathrm{V}_{\mathbf{T}}$ and $\mathrm{A}-\mathrm{aD}$ after hyperventilation are illustrated in Figure 6 . In neither case was the change significantly different from that in the control subjects.

c) Hyperventilation, breathing air, supine. Individual values for $A-a D$ and $V_{D} / V_{T}$ are given in Table VII and the mean results in Table X.
The average expired volume during hyperventilation was $22.7 \mathrm{~L}$ per minute, and the average $\mathrm{Pa}_{\mathrm{CO}_{2}}$ was $23.9 \mathrm{~mm} \mathrm{Hg}$. In two subjects $\mathrm{V}_{\mathbf{D}} / \mathrm{V}_{\mathbf{T}}$ increased after hyperventilation, but there was no change in the remaining two subjects. The mean changes in $V_{\mathbf{D}} / \mathrm{V}_{\mathbf{T}}$ and $\mathrm{A}-\mathrm{aD}$ are illustrated in Figure 7 ; there was a significant increase $(p<$ $0.05)$ in $\mathrm{V}_{\mathrm{D}} / \mathrm{V}_{\mathrm{T}} 10$ minutes after hyperventilation, but not at subsequent times, and $\mathrm{A}-\mathrm{aD}$ remained unaltered.

d) Effects of the infusion of angiotensin after hyperventilation. These subjects, who hyperventilated breathing air in the sitting position received an infusion of angiotensin about $35 \mathrm{~min}$ utes later. In three subjects this was followed by an immediate fall in $V_{D} / V_{T}$ to the control value before hyperventilation, and there was no rise when the infusion ceased. No change was observed in the remaining subjects, and there was no alteration in $\mathrm{A}-\mathrm{aD}$.

TABLE $\mathrm{X}$

Mean values in four subjects before and after hyperventilation, breathing air, in supine position*

\begin{tabular}{|c|c|c|c|c|c|c|c|c|c|}
\hline Timet & $\mathrm{PAO}_{2}$ & $\mathrm{PaO}_{2}$ & A-aD & $\mathrm{PaCO}_{2}$ & $\mathbf{R}_{\mathbf{E}}$ & $\begin{array}{l}\text { VD physiol. } \\
\text { BTPS }\end{array}$ & $\begin{array}{l}\mathrm{V}_{\mathrm{T}} \\
\text { BTPS }\end{array}$ & $\mathrm{V}_{\mathrm{D}} / \mathrm{V}_{\mathrm{T}}$ & $\begin{array}{l}\dot{\mathrm{V}}_{\mathrm{A}} \\
\mathrm{BTPS}\end{array}$ \\
\hline $\min$ & $m m \mathrm{Hg}$ & $m m \mathrm{Hg}$ & $m m H g$ & $m m H g$ & & $m l$ & $m l$ & $\%$ & $L / \min$ \\
\hline Control & 99.4 & 89.9 & 9.5 & 41.3 & 0.835 & 134 & 533 & 25.1 & 5.0 \\
\hline Control & 99.0 & 90.6 & 8.4 & 41.5 & 0.822 & 146 & 584 & 25.0 & 5.9 \\
\hline 10 & 89.5 & 81.9 & 7.6 & 41.3 & 0.740 & 148 & 464 & 31.9 & 3.6 \\
\hline 20 & 93.6 & 85.7 & 7.9 & 41.7 & 0.752 & 143 & 509 & 28.1 & 4.4 \\
\hline 30 & 99.0 & 91.1 & 7.9 & 40.3 & 0.815 & 154 & 556 & 27.7 & 5.1 \\
\hline 45 & 96.6 & 88.6 & 8.0 & 41.1 & 0.800 & 142 & 535 & 26.5 & 5.1 \\
\hline 60 & 99.4 & 89.9 & 9.5 & 40.6 & 0.841 & 165 & 627 & 26.3 & 6.0 \\
\hline
\end{tabular}

* Abbreviations as in Table I.

$\dagger$ Time from end of period of hyperventilation. 


\section{Discussion}

In the present studies alterations in the singlebreath oxygen test have been taken to indicate changes in the distribution of alveolar ventilation, and $\mathrm{A}-\mathrm{aD}$ for oxygen and the physiological dead space have been used as indexes of disturbances of ventilation-perfusion ratios in the lung. It is difficult to compare values for physiological dead space in different circumstances, unless tidal volume remains constant. Physiological dead space forms a constant proportion of tidal volume over a considerable range of values for the latter, and only when tidal volume is very large does the ratio $V_{D} / V_{T}$ decrease $(12,13)$. It has been assumed, therefore, that within the range of tidal volumes encountered in the present studies, a change in the ratio $V_{D} / V_{T}$ represents a change in physiological dead space.

Effects of carbachol aerosols and dust. Alveolar ventilation was less evenly distributed after the inhalation of either a carbachol aerosol or calcium carbonate dust, and both of these agents

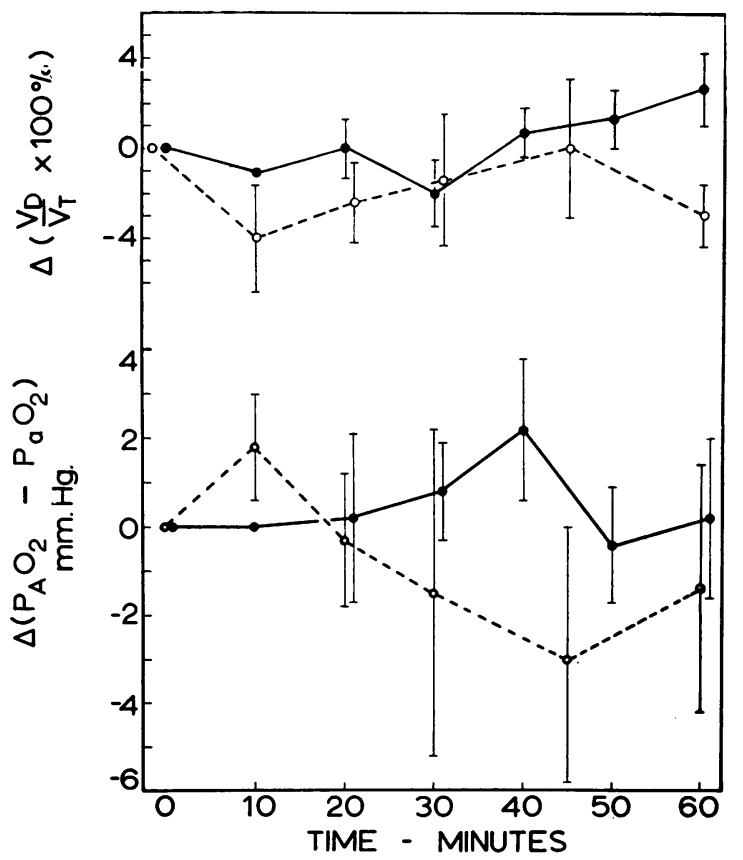

Fig. 6. Change in Physiological dead SPACE AND ALVEOLAR-ARTERIAL DIFFERENCE IN OXYGEN TENSION AFTER HYPERVENTILATION, IN SITTING POSITION, BREATHING AIR To WHICH 3 тo $5 \% \mathrm{CO}_{2}$ HAD BEEN ADDED. Hyperventilation ceased at zero time. Mean values $\pm \mathrm{SE}$ for four subjects who hyperventilated are shown by broken line and for five control subjects by the continuous line.

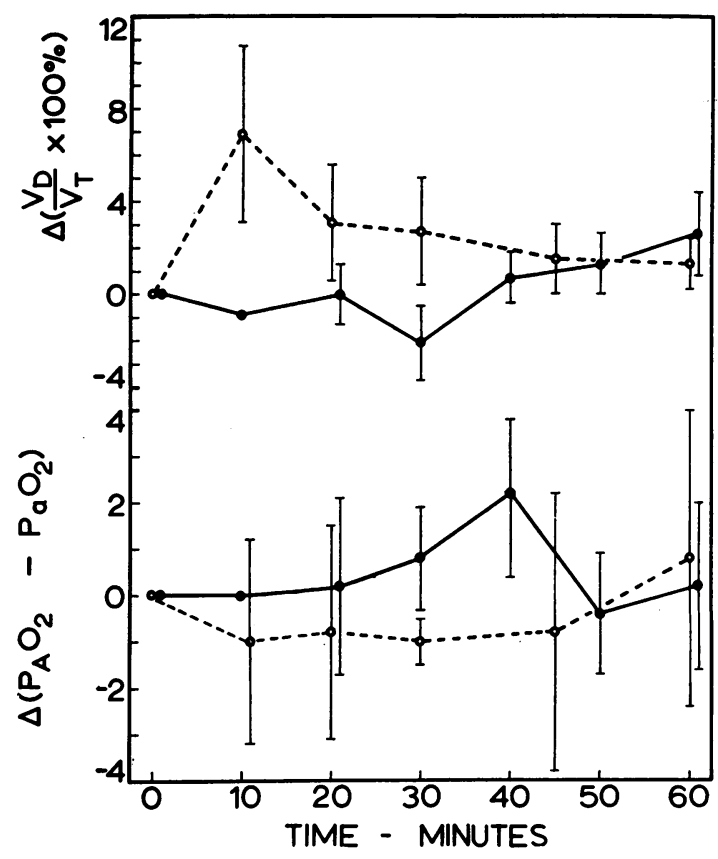

Fig. 7. Change in Physiological dead space and ALVEOLAR-ARTERIAL DIFFERENCE IN OXYGEN TENSION AFTER HYPERVENTILATION IN SUPINE POSITION, BREATHING AIR. Hyperventilation ceased at zero time. Mean values $\pm \mathrm{SE}$ for four subjects hyperventilated are shown by broken line and for five control subjects by the continuous line.

also reduced alveolar ventilation. This increased unevenness of the distribution of ventilation was accompanied by an increase of both $\mathrm{A}-\mathrm{aD}$ for oxygen and $V_{D} / V_{T}$, although physiological dead space itself did not change. The increase was greatest within a few minutes of breathing the bronchoconstrictor materials, and both returned to normal during the subsequent hour. There was a considerable variation between individual subjects in the extent of the response to bronchoconstrictors, which is consistent with the observations of McDermott (3) concerning the changes in airway resistance.

In general, the effects of carbachol and dust were similar although the $\mathrm{A}-\mathrm{aD}$ returned to normal more rapidly after dust than after carbachol. In one respect, however, the effects of the two materials differed; although $\mathrm{V}_{\mathrm{D}} / \mathrm{V}_{\mathrm{T}}$ increased after breathing calcium carbonate dust, there was no change after carbachol inspiration. Interpretation of the change in physiological dead space would have been easier if anatomical dead space had also been measured simultaneously. The few mea- 
surements made suggested that anatomical dead space decreased after carbachol, which constricts the major bronchi, but not after calcium carbonate dust. It is therefore deduced that after both carbachol and dust there was an increased frequency of high rentilation-perfusion ratios in the lungs.

Hyperventilation in the sitting position was shown to cause a prolonged increase in $V_{D} / V_{T}$, and the possibility was therefore considered that the changes after breathing dust or carbachol aerosol might have been the result of associated hyperventilation. The extent to which ventilation increased when breathing the bronchoconstrictor agents was certainly less than in the hyperventilation experiments, but its effect upon $\mathrm{Pa}_{\mathrm{CO}_{2}}$ was not measured. Although $\mathrm{V}_{\mathrm{D}} / \mathrm{V}_{\mathrm{T}}$ increased after both carbachol and dust, as after hyperventilation, there was also an increase in $\mathrm{A}-\mathrm{aD}$ that was not seen following hyperventilation, which is therefore unlikely to have caused the changes observed after the bronchoconstrictor agents.

Of the components of the $\mathrm{A}-\mathrm{aD}$, that due to the effects of diffusion limitation in the lung can be neglected. It is thought to be small when breathing air, and there is no reason to believe that this changed when the bronchoconstrictor agents were administered. The increase of $\mathrm{A}-\mathrm{aD}$ could represent a greater blood flow through anatomical communications between the venous and arterial systems. Carbachol undoubtedly entered the systemic circulation, giving rise to flushing and in one case to a desire to micturate. It is possible that carbachol increased venous admixture through bronchial or Thebesian veins which drain into the pulmonary veins or left ventricle, or through intrapulmonary shunts. Such a mechanism, however, seems unlikely in the subjects who breathed calcium carbonate dust. The more probable explanation of the increased $\mathrm{A}-\mathrm{aD}$ is that ventilation-perfusion ratios in the lung were altered, so that their distribution was over a wider range. This interpretation is supported by the accompanying increase in $V_{D} / V_{T}$ in the subjects who breathed dust, without any change in anatomical dead space.

The $\mathrm{A}-\mathrm{aD}$ and $\mathrm{V}_{\mathrm{D}} / \mathrm{V}_{\mathbf{T}}$ remained increased for a shorter time than the nitrogen concentration difference in the single-breath test. Eight minutes after inhaling dust and 16 minutes after inhaling carbachol, the distribution of ventilation-perfusion ratios had returned to normal, but this was not due to re-establishment of normal ventilation. DuBois and Dautrebande (1) reported significantly increased airway resistance up to $58 \mathrm{~min}$ utes and changes in compliance up to 45 minutes after inhalation of similar amounts of inert dusts. Constantine and associates (2) and McDermott (3) found that airway resistance was still markedly increased at minute 45 and 1 hour, respectively. It is possible that changes in the singlebreath nitrogen test were a more sensitive index of uneven ventilation than were changes in $\mathrm{A}-\mathrm{aD}$ and $V_{D} / V_{T}$ of uneven ventilation-perfusion ratios. This point is difficult to establish, but it seems unlikely, since in two subjects ventilation was sufficiently disturbed to produce changes in $\mathrm{A}-\mathrm{aD}$ and $\mathrm{V}_{\mathrm{D}} / \mathrm{V}_{\mathbf{T}}$ without detectable alteration in the nitrogen concentration difference.

An alternative explanation is that a mechanism exists by which perfusion is adjusted to maintain normal ventilation-perfusion relationships throughout the lung, after an acute disturbance of the distribution of ventilation. This could result from vasoconstriction of vessels supplying poorly ventilated alveoli, which are consequently hypoxic. Although no firm conclusions can be drawn, this possibility merits further investigation, especially in subjects who breathe inert dust, in whom a direct action on the pulmonary blood vessels is unlikely.

It is not possible to state the concentration of dust which these subjects breathed, but it was comparable to that used in the studies of airway resistance $(1,2)$. McDermott (3) has shown that similar increases in airway resistance result from more prolonged exposure to concentrations of dust commonly encountered in certain industrial processes.

Effects of voluntary hyperventilation. The validity of measurements made after the disturbance of the steady state by hyperventilation must be considered. During the period of hyperventilation carbon dioxide was lost from the body, and after this period it was retained. Estimates of alveolar oxygen tension from the alveolar gas equation will be in error if during the period of gas collection, the volume of carbon dioxide entering the lungs from the blood is greatly different from the volume excreted in the expired gas, that 
is, if $\mathrm{Pa}_{\mathrm{CO}_{2}}$ is rising or falling rapidly. Similarly, an estimate of physiological dead space is likely to be incorrect if $\mathrm{Pa}_{\mathrm{CO}_{2}}$ changes markedly during the period of measurement.

From measurements in five subjects, it was concluded that an average of $1,100 \mathrm{ml}$ carbon dioxide was lost during the 3 minutes of hyperventilation. Three minutes after hyperventilation the average rate of carbon dioxide retention was about $100 \mathrm{ml}$ per minute; presumably the rate of retention had been greater immediately after hyperventilation ceased. Although $\mathrm{Pa}_{\mathrm{CO}_{2}}$ remained low 2 minutes after hyperventilation, it had returned to its previous value by 10 minutes after hyperventilation. It was concluded that from 10 minutes onwards there was no appreciable retention of carbon dioxide and that a steady state had been restored. Arterial and alveolar carbon dioxide tensions had become stable, and determinations of alveolar oxygen tension and of physiological dead space after this time therefore appeared valid.

The subjects who were studied in the sitting position and breathing air showed a considerable increase in both physiological dead space and $\mathrm{V}_{\mathrm{D}} / \mathrm{V}_{\mathrm{T}}$ after hyperventilation. Since it was also shown that anatomical dead space did not change after hyperventilation, this change indicates that the ventilation-perfusion ratio in some alveoli had increased. This increase could have resulted from a disproportionate increase in the ventilation of these alveoli or from a decrease in their perfusion. It is possible that after hyperventilation, the pattern of alveolar ventilation was altered in such a way that some alveoli became better ventilated. There is no reason to believe that this did occur, and the single-breath test provided no evidence of an alteration in the distribution of ventilation. Furthermore a change of distribution in this way, associated with an unchanged or decreased total alveolar ventilation would also lead to an increase in the $\mathrm{A}-\mathrm{aD}$ for oxygen, whereas a small decrease was actually observed.

The small reduction $\mathrm{A}-\mathrm{aD}$, although statistically not significant at any one time, was consistent at each measurement after hyperventilation. It was associated with a small decrease in $\mathrm{PA}_{\mathrm{O}_{2}}$, which as we have previously shown (14) would be expected to lead to a decrease in $\mathrm{A}-\mathrm{aD}$. The magnitude of the change after hyperventilation was, however, rather more than would have been predicted from the change in $\mathrm{PA}_{\mathrm{O}_{2}}$. The decrease in $\mathrm{A}-\mathrm{aD}$ could be explained either by increased ventilation or decreased perfusion of some alveoli which before were relatively poorly ventilated; from the previous argument the latter seems the more probable.

In the normal subject in the erect position, the upper parts of the lung are both poorly perfused and relatively poorly ventilated (15), although the former is more pronounced, so that the ventilation-perfusion ratio of the upper zones is greater than the average for the whole lung. Since the changes we observed were only significant in subjects in the erect posture, it is suggested that they resulted from a decrease in blood flow to the upper parts of the lung. Since these areas have predominantly high ventilation-perfusion ratios, the effect upon physiological dead space was much more prominent than the change in $\mathrm{A}-\mathrm{aD}$.

The fall in blood flow to the upper parts of the lung presumably resulted from a fall in perfusing pressure, and the results also suggest that this effect was mediated by a change in carbon dioxide tension. It has been shown that hyperventilation in the supine position causes an increase in cardiac output $(16,17)$, even if a fall in $\mathrm{PCO}_{2}$ is prevented (18). Burnum, Hickam, and McIntosh (19) reported a fall in systemic blood pressure due to vasodilatation, and the decrease in systemic vascular resistance was prevented by addition of carbon dioxide to the inspired gas during hyperventilation $(19,20)$. Nothing is known of the effects upon the pulmonary circulation, but the systemic vasodilation might lead to pooling of blood in the peripheral vessels with a consequent fall in pulmonary arterial pressure, especially in the upright position.

There remains to consider the reason for the persistence of the increase in physiological dead space for 60 minutes after hyperventilation. The effects of hyperventilation on $\mathrm{PaCO}_{2}$ lasted for no more than 10 minutes, and there is no published evidence that the circulatory effects last any longer than this. It therefore appears that apical blood flow decreased because of a fall in perfusing pressure, but was not restored when that pressure returned to its former value. Such an occurrence could be explained by the closure of some blood 
vessels when the pressure within them fell below a certain level and by their failure to reopen until a somewhat higher pressure was reached.

In further experiments an attempt was made to raise the pulmonary intravascular pressure by intravenous infusion of angiotensin. This is known to raise both pulmonary arterial and wedge pressure in the supine position (21), and we have some evidence that it has a similar but smaller effect in the sitting position. The results were inconclusive, perhaps in part because the magnitude of the rise in pulmonary intravascular pressures in these subjects may have been variable. The positive results are, however, consistent with the hypothesis of a critical opening pressure in the pulmonary blood vessels of the upper parts of the lung.

\section{Summary}

Aerosols of carbachol and clouds of calcium carbonate dust were administered to normal subjects, and both disturbed the evenness of alveolar ventilation as measured by the single-breath oxygen test.

After carbachol aerosol inspiration, there was an increase in alveolar-arterial difference in oxygen tension $(\mathrm{A}-\mathrm{aD})$, no change in the ratio of physiological dead space to tidal volume $\left(\mathrm{V}_{\mathrm{D}} / \mathrm{V}_{\mathrm{T}}\right)$, and a decrease in anatomical dead space.

After breathing dust clouds, $\mathrm{A}-\mathrm{aD}$ increased and so did $V_{D} / V_{T}$, but there was no change in anatomical dead space.

Both $\mathrm{A}-\mathrm{aD}$ and physiological dead space returned to control values sooner than did the singlebreath oxygen tests. The possibility that this indicates a local redistribution of pulmonary capillary blood flow in response to the acute disturbance of distribution of alveolar ventilation is discussed.

After a brief period of voluntary hyperventilation in the sitting position, there was an increase in physiological dead space and in $V_{D} / V_{T}$ that persisted for 60 minutes but only a small and nonsignificant decrease in $\mathrm{A}-\mathrm{aD}$.

When a fall in $\mathrm{PCO}_{2}$ was prevented by addition of carbon dioxide to the inspired gas during hyperventilation, there was no significant alteration in $\mathrm{V}_{\mathrm{D}} / \mathrm{V}_{\mathrm{T}}$ or $\mathrm{A}-\mathrm{aD}$.

Subjects who hyperventilated, breathing air in the supine position, showed hardly any change in $\mathrm{V}_{\mathrm{D}} / \mathrm{V}_{\mathrm{T}}$ and no alteration in $\mathrm{A}-\mathrm{aD}$.

It is postulated that hypocapnia during hyperventilation may lead to a fall in pulmonary arterial pressure and a decreased blood flow to the upper zones of the lung; the possible mechanisms are discussed.

\section{Acknowledgments}

We are indebted to Mr. J. W. Skidmore of the M.R.C. Pneumoconiosis Research Unit for the measurements of particle size and to Mrs. Anne Hollyhock for her excellent technical assistance.

\section{References}

1. DuBois, A. B., and L. Dautrebande. Acute effects of breathing inert dust particles and of carbachol aerosol on the mechanical characteristics of the lungs in man. Changes in response after inhaling sympathomimetic aerosols. J. clin. Invest. 1958, $37,1746$.

2. Constantine, H., L. Dautrebande, N. Kaltreider, F. W. Lovejoy, Jr., P. Morrow, and P. Perkins. Influence of carbachol and of fine dust aerosols upon the breathing mechanics and the lung volumes of normal subjects and of patients with chronic respiratory disease before and after administering sympatheticomimetic aerosols. Arch. int. Pharmacodyn. 1959, 123, 239.

3. McDermott, M. Acute respiratory effects of the inhalation of coal-dust particles. J. Physiol. (Lond.) 1962, 162, 53P.

4. Bishop, J. M., and J. M. Raine. Changes in ventilation-perfusion relationships in the lung after hyperventilation in The Regulation of Human Respiration. Oxford, Blackwell Scientific Publications, 1963 , p. 561 .

5. Bishop, J. M. The measurement of blood oxygen tension. Proc. roy. Soc. Med. 1960, 53, 177.

6. Asstrup, P. A simple electrometric technique for the determination of carbon dioxide tension in blood and plasma, total content of carbon dioxide in plasma, and bicarbonate content in «separated» plasma at a fixed carbon dioxide tension $(40 \mathrm{~mm}$ $\mathrm{Hg}$ ). Scand. J. clin. Lab. Invest. 1956, 8, 33.

7. Comroe, J. H., Jr., and W. S. Fowler. Lung function studies VI. Detection of uneven alveolar ventilation during a single breath of oxygen. Amer. J. Med. 1951, 10, 408.

8. Kjellmer, I., L. Sandqvist, and E. Berglund. "Alveolar plateau" of the single breath nitrogen elimination curve in normal subjects. J. appl. Physiol. 1959, 14, 105.

9. Fowler, W. S. Lung function studies II. The respiratory dead space. Amer. J. Physiol. 1948, 154, 405. 
10. Wright, B. M. A new nebuliser. Lancet 1958, 2, 24.

11. Wright, B. M. A new dust-feed mechanism. J. sci. Instrum. 1950, 27, 12.

12. Cooper, D. Y., and C. J. Lambertsen. Effect of changes in tidal volume and alveolar $\mathrm{pCO}_{2}$ on physiological dead space. Fed. Proc. 1956, 15, 39.

13. Severinghaus, J. W., and M. Stupfel. Alveolar dead space as an index of distribution of blood flow in pulmonary capillaries. J. appl. Physiol. 1957, 10, 335.

14. Raine, J. M., and J. M. Bishop. A-a difference in $\mathrm{O}_{2}$ tension and physiological dead space in normal man. J. appl. Physiol. 1963, 18, 284.

15. West, J. B., and C. T. Dollery. Distribution of blood flow and ventilation-perfusion ratio in the lung, measured with radioactive $\mathrm{CO}_{2}$. J. appl. Physiol. 1960, 15, 405.

16. Ross, J. C., R. Frayser, and J. B. Hickam. A study of the mechanism by which exercise increases the pulmonary diffusing capacity for carbon monoxide. J. clin. Invest. 1959, 38, 916.

17. Donevan, R. E., N. M. Anderson, P. Sekelj, O. Papp, and M. McGregor. Influence of voluntary hyperventilation on cardiac output. J. appl. Physiol. 1962, 17, 487.

18. Turino, G. M., M. Brandfonbrenner, and A. P. Fishman. The effect of changes in ventilation and pulmonary blood flow on the diffusing capacity of the lung. J. clin. Invest. 1959, 38, 1186.

19. Burnum, J. F., J. B. Hickam, and H. D. McIntosh. The effect of hypocapnia on arterial blood pressure. Circulation 1954, 9, 89.

20. Richardson, D. W., A. J. Wasserman, and J. L. Patterson, Jr. General and regional circulatory responses to change in blood $\mathrm{pH}$ and carbon dioxide tension. J. clin. Invest. 1961, 40, 31.

21. Segel, N., P. Harris, and J. M. Bishop. The effects of synthetic hypertensin on the systemic and pulmonary circulation in man. Clin. Sci. 1961, 20, 49.

\section{ERRATUM}

In the paper entitled, "On the Concentrating Defect in Cirrhosis of the Liver," by Hershel Jick, Donald E. Kamm, Julian G. Snyder, Robert S. Morrison, and Thomas C. Chalmers, published in the February issue (p. 258), the following corrections should be noted: On page 259 and in the last column of Tables III and IV, the percentage of urea per nonurea solute should read percentage of urea per total solute excretion. The last column of numbers in Table III, beginning with $\mathrm{Pa}-$ tient 1 , should be $44,65,55,29,45,68,20,43,19,65$, and 47 . 